\title{
CIÊNCIA NA \\ PROGRAMAÇÃO DA TV COMERCIAL ${ }^{1}$
}

\section{Aliar entretenimento e ciência é o desafio da programação científica na televisão}

"A ciência às vezes se vê como impessoal, como pensamento puro, desvinculado de suas origens históricas e humanas. E frequientemente é ensinada como se assim fosse de fato. No entanto, a ciência representa um empreendimento humano em toda a sua extensão, um desenvolvimento humano, orgânico e progressivo, com impulsos e paradas repentinas e, também, desvios bizarros. Ela cresce de seu passado, mas nunca o ultrapassa, como nós mesmos não ultrapassamos nunca nossa infância."

\section{Oliver Sacks}

A presença da ciência na televisão brasileira praticamente se resume à veiculação de matérias nos telejornais, anunciando a descoberta de uma supernova em galáxia distante ou o desenvolvimento de um medicamento eficaz contra a impotência. São cada vez mais raros os programas especializados em divulgação de ciência compromissados com a qualidade da informação e com a formação científica do público telespectador.

Nos últimos anos, houve um sistemático desaparecimento desses programas espe- cializados. Relegados pelas emissoras de televisão a horários periféricos, naturalmente de baixa audiência, sofreram com a ausência de visibilidade. Por esta mesma razão, não tiveram a oportunidade de estabelecer vínculos estreitos com o público, conquistar telespectadores e consolidar sua presença na programação. Muitos perderam o patrocínio que sustentava a produção e conseqüentemente deixaram de ter espaço garantido na grade das emissoras comerciais ou educativas em que eram exibidos.

Esse foi o fim de programas como Estação ciência, da TV Manchete, Academia Amazônia, da TV Cultura, além de diferentes títulos produzidos pela Fundação Roquete Pinto como Tome ciência, Eco-realidade, Universidade e Paidéia, todos exibidos pela TV Educativa. Dessa grande leva de programas especializados, o Globo Ciência, reconhecido como o programa pio-

\section{A AUTORA}

\section{Lacy Barca}

Jomalista, gerente de Ciência e Ecologia da Fundação Roberto Marinho.

1. Ciência e Comunicação na TV comercial, 14 anos de programa Globo Ciência é o título original deste artigo, apresentado no 1 Congresso Internacional sobre Comunicação e Educação, realizado em maio, 1998, em São Paulo. 
neiro de divulgação científica na televisão brasileira $^{2}$, é o único sobrevivente. Produzido pela Fundação Roberto Marinho, o programa foi lançado em outubro de $1984 \mathrm{e}$ está até hoje no ar, todo sábado de manhã.

O desaparecimento de tantos programas não foi sequer registrado pelo público. Parece que eles não fizeram muita falta para o telespectador. Apenas alguns representantes da comunidade científica, em discursos nas reuniões anuais da Sociedade Brasileira para o Progresso da Ciência SBPC, chegaram a reclamar a perda das tribunas a partir das quais obtinham um contato privilegiado com a opinião pública.

Ao mesmo tempo, a TV por assinatura chegou ao Brasil e foram lançados vários novos canais de televisão com documentários e programas de ciência como peças de resistência da programação. Alguns desses canais, como o Discovery (TVA/NET) e o Mundo (TVA), são integralmente dedicados a programas do gênero. $O$ conhecimento científico é a estrela dessas emissoras, seja através de documentários sobre o mundo animal ou em programas que mostram os mais recentes avanços da pesquisa tecnológica de ponta.

O crescimento do mercado, com o advento da $\mathrm{TV}$ por assinatura, também provocou o incremento da produção regular de programas científicos em várias emissoras públicas ou privadas do mundo.

A $B B C$ e o Channel 4, da Inglaterra; a $P B S$ e a $W G B H$ dos Estados Unidos; a $Z D F$ e a WDR da Alemanha; La Cinquiéme, da França; e $A B C$, da Austrália, são alguns exemplos de emissoras que mantêm programas científicos em destaque na programação, em horário nobre, obtendo altos índices de audiência e, conseqüentemente, recursos para produzir mais e com maior padrão de qualidade, atendendo, ao mesmo tempo, às exigências do público e obtendo lucros ao fornecê-los para emissoras por assinatura.

$\mathrm{Na}$ contramão dessa história, a televisão brasileira vive uma crise na produção de programas de ciência. Alguns aspectos que fazem parte do leque de problemas, os quais se passam a analisar, são o interesse do público pela temática, a atratividade da linguagem audiovisual adotada e as oportunidades - comerciais ou não - que programas desse tipo oferecem para as emissoras.

\section{PÚBLICO}

Haverá um real interesse do público pela ciência? Qual é o grau de curiosidade da população em relação ao funcionamento da natureza? Esta curiosidade é forte o suficiente para fazer as pessoas ligarem a TV de manhã, bem cedo?

Há quase quinze anos, o Ministério de Ciência e Tecnologia encomendou ao Instituto Gallup uma pesquisa nacional para saber o que o brasileiro pensa de ciência e tecnologia. De lá para cá, as opiniões podem ter mudado, mas não há novos dados disponíveis. Podemos dizer, portanto, que quinze anos atrás, sete em cada dez brasileiros se interessavam por descobertas científicas. Dois terços da população, segundo as conclusões do estudo, cobravam dos meios de comunicação um noticiário mais consistente e reflexivo sobre os avanços da ciência e as mudanças que as novas tecnologias trariam ao seu cotidiano.

De certa forma, os meios de comunicação responderam aos anseios do público com a ampliação da cobertura de assuntos

2. PRETTO, N. A ciência nos meios de comunicação. Tecnologia Educacional. Rio de Janeiro: Associação Brasileira de Tecnologia, v. 21, nov./dez. 1992. 
científicos em programas semanais veiculados em horário nobre, dos quais alguns exemplos são o Fantástico e o Globo repórter, da Rede Globo de Televisão, e o Programa de domingo, da Rede Manchete. Em seu artigo Ciência nos meios de comunicação $o^{3}$ o professor Nelson Pretto, da Universidade Federal da Bahia, lembra que as matérias sobre ciência nesses programas eram produzidas basicamente por correspondentes estrangeiros das emissoras, abordando assuntos da ciência e da tecnologia nos países desenvolvidos, especialmente nos Estados Unidos. De acordo com Pretto, "a tônica destas matérias de divulgação científica era, na maioria das vezes, sensacionalista". Para ele, "o aspecto mais forte deste estilo de reportagem está no fato de apresentar a ciência, e principalmente os cientistas, de forma extremamente caricatural"4.

É na esteira de críticas como esta que surgem os programas especializados, preocupados em consolidar a formação científica do telespectador. Em sua campanha de lançamento, o pioneiro Globo Ciência afirmava seus propósitos de explicitar a metodologia científica, revelar o funcionamento da natureza, acompanhar os processos de desenvolvimento tecnológico, discutir os conflitos técnicos e éticos do progresso e, principalmente, levar o jovem a vivenciar a aventura da ciência, estimulando a formação de novas geraçōes de cientistas.

Com esses pressupostos, o programa definia, ainda, o seu target (alvo): o público jovem, embora fosse veiculado em horário inadequado para esta faixa da população sábado às $7 \mathrm{~h} 30 \mathrm{~min}$ da manhã.
Hoje, em seu décimo quinto ano de existência, e ainda sendo exibido no mesmo horário, pode-se dizer que os princípios filosóficos do conteúdo do programa continuam os mesmos. Na escolha dos assuntos e na produção de imagens e entrevistas há, também, o cuidado de descobrir a melhor maneira de informar, educar e divertir.

Esta preocupação constante determinou e continua determinando modificações radicais na linguagem audiovisual do Globo Ciência.

\section{LINGUAGEM}

Um estúdio, uma bancada, um apresentador sorridente e sentado, apresentando matérias pré-gravadas em laboratórios de universidades e centros de pesquisa. A fala autorizada dos cientistas em seu ambiente de trabalho, corroborando os pressupostos enunciados e a linha de raciocínio conduzida pelo apresentador. Foi este o estilo narrativo escolhido pelos profissionais de televisão que formataram o Globo Ciência para o seu lançamento, em 1984. Uma linguagem tradicional, muito comum nos programas jornalísticos da época.

Com um ano de vida o programa sofreu as primeiras modificações visuais e narrativas. Ganhou um estúdio maior, um cenário e uma apresentadora que já podia caminhar. As matérias pré-gravadas passaram a ser conduzidas por um repórter em campo, conferindo maior credibilidade à informação e possibilitando a inclusão de mais um ponto de vista na argumentação. Havia, então, três falas: a do apresentador, a do repórter e a do cientista.

Nesta fase, o programa começou a decolar, conquistando o Prêmio José Reis de 
Digulgação Científica, do Conselho Nacional de Desenvolvimento Científico e Tecnológico - $\mathrm{CNPq}$, e realizando suas primeiras matérias internacionais: na Antártida, em Portugal, na França e nos Estados Unidos.

$\mathrm{O}$ amadurecimento narrativo deu o impulso necessário à libertação formal. Com três anos de idade, o Globo Ciência assumiu o estilo documentário jornalístico, dispensando a apresentação em estúdio e possibilitando que os repórteres conduzissem o programa inteiramente em campo, vivenciando a matéria no local onde estavam os fatos. Se de um lado esta opção diminuiu a diversidade de pontos de vista narrativos, de outro possibilitou o estabelecimento de uma relação mais quente e direta entre o programa e o público, sem a interposição fria do apresentador em estúdio. $\mathrm{O}$ programa ganhou em ritmo e atualidade. Conquistou três prêmios internacionais e um nacional e viajou de novo à Antártida, Portugal e Estados Unidos. Foi também à China, acompanhar o desenvolvimento de satélites artificiais por brasileiros. Mas apesar de todo o prestígio e reconhecimento internacional, os números da audiência nacional mantinham-se estáveis ou descendentes. O programa perdia público, pecado mortal numa emissora comercial, mesmo às 7h30min da manhã de sábado.

Era preciso mudar. Aos sete anos de idade o Globo Ciência passou por sua primeira grande transformação. A partir das conclusões de uma pesquisa de opinião realizada junto ao público, o programa foi inteiramente reformulado, em forma e conteúdo. Abandonou a linha documental e monotemática, adotando o estilo revista, com a abordagem de seis a oito temas diferentes por programa. Ganhou nova vinheta gráfica, novos apresentadores e repórteres, material internacional e uma tímida pitada de humor, muitas vezes desajeitada e carica- tural. O resultado desse cruzamento, um produto um tanto híbrido, manteve estáveis os níveis de audiência por algum tempo.

Mas há uma fatia de público, uma parcela considerável da população que estava diante da televisão no sábado pela manhã, que ainda não havia sido conquistada pelo programa: as crianças.

Novas pesquisas foram feitas e o programa passou por outra grande transformação. Em 1995, foi criada a Turma do Globo Ciência, composta por cinco apresentadores, sendo três jovens, uma criança e um homem mais velho, experiente e culto. As possibilidades narrativas desse conjunto de apresentadores se revelaram consideravelmente mais amplas, abrindo espaço para a utilização de recursos dramatúrgicos, construção de esquetes bem humoradas e também para a documentação e a aventura.

Entretanto, o texto permaneceu eminentemente jornalístico, transferindo a responsabilidade da fala autorizada para o cientista e, com isso, criando dentro do mesmo programa duas linguagens distintas. A dos apresentadores, descontraída e bem humorada, e a das matérias jornalísticas e entrevistas com cientistas, fria e distante.

Ao longo de três anos, as crianças que apresentavam o programa cresceram e a Turma pode ter perdido o impacto, a originalidade e a empatia que estabelecia com o público infantil. Observou-se que, no mesmo horário, emissoras concorrentes ganharam audiência transmitindo programas de animação, diretamente voltados para crianças.

\section{DESAFIOS}

Para conquistar telespectadores e fazer frente à concorrência a que está sujeita uma televisão comercial, é fundamental estabelecer a comunicação com quem está em casa 
assistindo ao programa. Não basta diversificar os apresentadores, é preciso que eles assumam o papel de facilitadores no processo de construção de uma narrativa inteligente, instigante e participativa, destinada a envolver o público e não permitir que ele mude de canal.

A ciência é pragmática e tem os dois pés fincados na realidade, no cotidiano. Isto faz com que a maioria dos programas de TV sobre ciência adotem a linguagem do jornalismo. Mas a ficcionalização do jornalismo é prática comum, criando a armadilha identificada por Marc Augé como "o novo regime de ficção que hoje nos afeta, contamina e penetra a vida social, a ponto de nos fazer duvidar dela, de sua realidade, de seu sentido e das categorias (identidade, alteridade) que a constituem e a definem. As reportagens de televisão adquirem uma aparência de ficção, e a ficção imita o real"'s.

Com base nos exemplos do cotidiano, sem precisar, necessariamente, adotar o jornalismo, um programa de televisão pode quebrar as muitas barreiras que separam o telespectador dos conceitos científicos.

Uma dessas barreiras é o preconceito bastante difundido de que a ciência é complexa demais para o entendimento do homem comum. Em artigo publicado na revista norte americana Mercury, Bruce Lewenstein, professor associado do Departamento de Estudos em Comunicação e Tecnologia da Universidade de Cornell, Nova York ${ }^{6}$, procura entender alguns desses mecanismos de defesa que fazem com que o público se recuse a abraçar a ciência.

Ele diz que a maioria dos cidadãos não quer saber por que a física é importante, mas se preocupa com questões práticas do tipo "vai chover amanhã?". Ou seja, a ciência é fundamental, mas não da maneira como os cientistas pretendem. Segundo Lewenstein, o conhecimento factual revela pouco sobre $o$ conhecimento científico em si.

A Associação Americana para o Avanço da Ciência - AAAS, em seu Projeto 2061, propõe currículo do ensino de ciências nas escolas públicas, reduzindo a transmissão de fatos e reforçando a compreensão dos processos científicos.

Seguindo essa tendência, de acordo com Renato José de Oliveira ${ }^{7}$, os processos científicos podem ser a grande atração dos veículos do chamado "ensino informal", caracterizados pelas revistas de divulgação científica, enciclopédias, programas de televisão, enfim a variada gama de meios extraescolares que constituem uma autêntica "escola paralela"8, como diria Mostafa, capaz de difundir conhecimentos para um público vasto e heterogêneo. Essa escola paralela tem características mais democráticas do que o ensino formal, porque não se restringe aos que estão sentados nos bancos escolares.

Outro obstáculo a ser enfrentado no caminho do aperfeiçoamento da narrativa de um programa que se dedica à divulgação científica é a tendência de encarar a ciência como feita e acabada, inquestionável e de aplicabilidade universal, passando a segundo plano a dúvida e o questionamento9.

5. AUGÉ, M. A guerra dos sonhos. Exercícios de etnoficção. São Paulo: Papirus, 1997.

6. LEWENSTEIN, B. O que o público deve saber sobre ciência. Mercury. Nova York: Universidade Cornell, jan./fev. 1995.

7. OLIVEIRA, R. J. As revistas de divulgação científica e a transmissão do conhecimento: uma abordagem sobre o ensino informal de ciências. Revista Contexto \& Educação. Ijuí, Rio Grande do Sul: UNIJUÍ, n. 32, out./dez. 1993.

8. MOSTAFA, S. E. Vulgarização científica: manifestação da ciência ou educação permanente? Ciência e Cultura. São Paulo: SBPC, jun. 199I.

9. OLIVEIRA, R. J. As revistas... op. cit. 
É indispensável lembrar a todo momento que o conhecimento científico se solidifica num processo permanente de questionamento da verdade estabelecida, no qual a dúvida tem papel fundamental.

O grande filósofo das ciências, Karl Popper, citado por Michel Rival ${ }^{10}$, disse certa vez que o caráter científico de uma teoria não depende de esta ser verificada ou verificável, mas de que se exponha de antemão a ser refutada pela experiência. Toda teoria deve se expor à sua própria refutação e, em última instância, a experiência tem a palavra final.

$O$ professor Bruce Lewenstein ensina que "para avançar no conhecimento público da ciência, temos que aprender mais sobre o público e seus interesses" ${ }^{\prime \prime}$. Este é um outro

Resumo: Este trabalho tem o objetivo de refletir sobre a presença de temas científicos na televisāo comercial brasileira e a linguagem adotada pelo meio para tratar desses temas. Discute as expectativas do telespectador quanto à informação em ciência e tecnologia e a contribuição de programas de divulgação de ciência na formação do jovem. Tem como referencial de análise o programa Globo Ciência, da Rede Globo de Televisão. Questiona, ainda, as formas de abordagem do fato científico e sua atratividade para o público telespectador, levando-se em consideração os indices de audiência compativeis com os interesses comerciais das emissoras.

Palavras-chave: divulgação cientifica, Globo Ciência, televisão, público, audiência desafio importante para o Globo Ciência, como um programa educativo: conhecer melhor o seu público.

Em meio a este processo de aperfeiçoamento permanente, talvez seja o caso de o programa entrar na escola para ouvir as crianças e estudar como elas aprendem ciência.

A disposição para enfrentar estes e outros desafios é o que tem garantido a sobrevivência do Globo Ciência. Para chegar a realizar 700 programas, foi necessário adotar modificações estratégicas na maneira de abordar o fato científico, tomando a iniciativa de modificar a linguagem audiviosual ao menor sinal de insatisfação do público e, principalmente, ao menor sinal de crescimento da audiência da concorrência, como acontece em qualquer emissora comercial.

Abstract: This work aims at reflecting on the presence of scientific themes in Brazilian commercial television and on the language adopted by the medium to treat these themes. It discusses the viewer's expectation concerning information in science and technology and the contribution certain scientific divulging programs have on young people's upbringing. The article uses for its analysis referential Rede Globo de Televisão's program Globo Ciência. It questions, furthermore, the manners of approaching the scientific fact and its attractiveness to the viewers, considering the rates of audience that are compatible with the stations' commercial interests.

Key words: scientific divulging, Globo Ciência, television, public, audience 